\title{
A ZERO EMISSION COMBUSTION POWER PLANT FOR ENHANCED OIL RECOVERY
}

\author{
GÖRAN WALL ${ }^{\dagger *}$, EUGENE I. YANTOVSKII \\ and \\ LARS LINDQUIST* and JOAKIM TRYGGSTAD* \\ * Department of Engineering, Kristianstad University, Box 59, S-291 21 Kristianstad, Sweden, email: \\ Goran.Wall@hks.se \\ ¥Institute for Energy Research, Russian Ac. Sci., 44/2 Vavilova St. 117333 Moscow, Russia
}

(Received 19 April 1993; received for publication 25 April 1995)

\begin{abstract}
We have studied an internal combustion $\mathrm{CO}_{2}$ power plant to enhance oil recovery. The plant has air separation of $\mathrm{O}_{2}$ for combustion and of $\mathrm{N}_{2}$ for injection, a combustion chamber, a turbine, a compressors, a recuperator, and a cooling tower. The oil-derived gases are used to produce liquid $\mathrm{CO}_{2}$, highly compressed $\mathrm{N}_{2}$, process steam and, if necessary, power. No exhaust gases are released. The plant design is presented along with efficiency calculations. The plant should be of interest for offshore oil production.
\end{abstract}

\section{INTRODUCTION}

$\mathrm{CO}_{2}$ cycles first appeared in 1940 but attracted little attention. ${ }^{1}$ The benefits of $\mathrm{CO}_{2}$ compared with $\mathrm{H}_{2} \mathrm{O}$ are low condensation heat and ability to be pumped to high pressure in the liquid state with good recuperation. Drawbacks are some toxicity, corrosion effects and a low cycle temperature $\left(\sim 600^{\circ} \mathrm{C}\right)$ in ordinary boilers with external combustion. Even after use of internal combustion to increase the temperature, the $\mathrm{CO}_{2}$ cycle remained unexplored. ${ }^{2}$ However, the concern of reducing $\mathrm{CO}_{2}$ emissions to atmosphere has brought attention to fuel combustion in a mixture of $\mathrm{O}_{2}$ and flue gases $\left(\mathrm{H}_{2} \mathrm{O}, \mathrm{CO}_{2}\right.$ or both). ${ }^{3-8}$ Efficiencies of $35-45 \%$ seem possible in spite of power use for $\mathrm{O}_{2}$ production. The main benefit of these cycles is zero-emission, i.e. no exhaust gases. Liquid $\mathrm{CO}_{2}$ is the only effluent.

Thermodynamic properties for internal combustion $\mathrm{CO}_{2}$ cycles are available ${ }^{9,10}$ and needed economic data were estimated by the authors. To improve the economics, Steinberg and many others proposed the use of $\mathrm{CO}_{2}$ for enhanced oil recovery (EOR). The benefit of this approach is well documented. ${ }^{11}$ About 1 ton of injected $\mathrm{CO}_{2}$ gives 0.5 ton of oil, which is admissible from a net-energy point of view. Laboratory tests have shown increased oil extraction from 54 to $96 \%$ at $120^{\circ} \mathrm{C}$ and 400 bar when flue gases were replaced by $\mathrm{CO}_{2}{ }^{12}$

We are familiar with the following processes: (i) The use of compressed $\mathrm{N}_{2}$ to support the flow of liquid $\mathrm{CO}_{2}$. (ii) Thermal EOR with steam or hot water as the energy carriers. (iii) The combustion of deep oil using injected $\mathrm{O}_{2}$. The OCDOPUS (Oil Enhancement Carbon Dioxide Oxygen Power Universal Supply) plant is a suggestion for a complete EOR power plant, producing power, $\mathrm{CO}_{2}, \mathrm{~N}_{2}, \mathrm{O}_{2}$, process steam, and hot water (see Fig.

\footnotetext{
$\dagger$ Author for correspondence.
} 
1). In addition to the eight processes shown in Fig. 1, cooling water is needed, e.g., sea water at an offshore plant.

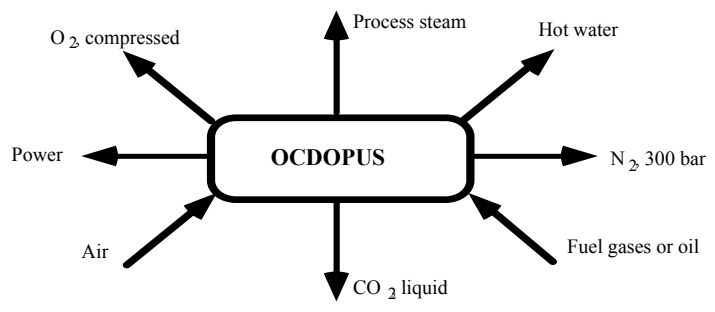

Fig. 1. The OCDOPUS plant: production and consumption.

\section{THE OCDOPUS PLANT}

The system of study is indicated by the dotted line in Fig. 2. Air is separated into $\mathrm{O}_{2}$ and $\mathrm{N}_{2}$ in unit 1 . In a real plant, this unit will account for half the size. $\mathrm{O}_{2}$ enters the combustion chamber 2 with recirculated $\mathrm{CO}_{2}$ and fuel. The combustion products (mainly $\mathrm{CO}_{2}$ ) expand in the turbine 8 and are cooled down in the recuperator 3 and cooling tower 4. After separation of water in unit 5 , the dry $\mathrm{CO}_{2}$ is compressed from 7 to 100 bar unit 10, which may be either an isothermal or an adiabatic process with additional recuperators. ${ }^{13}$

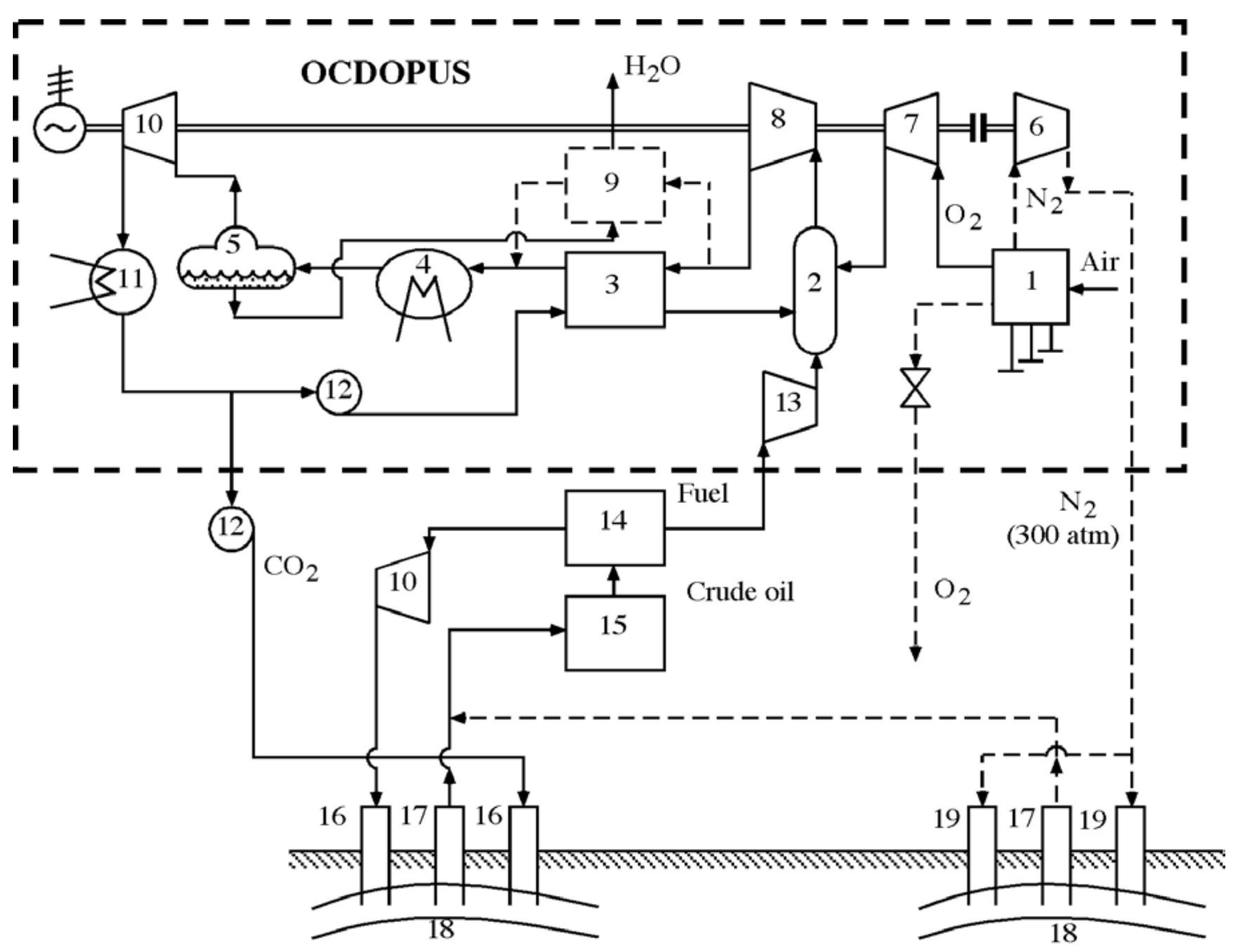

Fig. 2. Schematic of the OCDOPUS plant. 1, air separation; 2, combustion chamber; 3, recuperator; 4, cooling tower; 5 , water separator; $6, \mathrm{~N}_{2}$ compressor; $7, \mathrm{O}_{2}$ compressor; 8 , turbine; 9 , steam production; 10 , $\mathrm{CO}_{2}$ compressor; $11, \mathrm{CO}_{2}$ condenser; $12, \mathrm{CO}_{2}$ pump; 13 , fuel-gas compressor; $14, \mathrm{CO}_{2}$ /fuel-gas separator;

15 , oil/gas separator; $16, \mathrm{CO}_{2}$ injection well; 17 , production well; 18 , reservoir; $19, \mathrm{~N}_{2}$ injection. 
The $\mathrm{CO}_{2}$ is condensed at 60 bar in unit 11 , liquid $\mathrm{CO}_{2}$ is pumped to 100 bar and returned to recuperator 3 . Water from combustion may be heated in unit 9 if process steam is needed. Liquid $\mathrm{CO}_{2}$ from combustion is injected into the well 16. The $\mathrm{N}_{2}$ compressor 6 is attached to the shaft by a switch. When the separated $\mathrm{N}_{2}$ is compressed and injected, the net power output equals zero.

\section{NUMERICAL RESULTS}

$T-S$ diagrams are presented in Figs. 3 and 4. The chemical composition of the fuel (oil gases) was assumed to be $\mathrm{C}_{6} \mathrm{H}_{14}$. The equation for complete combustion becomes

$$
(1 / 6) \mathrm{C}_{6} \mathrm{H}_{14}+(19 / 12) \mathrm{O}_{2} \rightarrow \mathrm{CO}_{2}+(7 / 6) \mathrm{H}_{2} \mathrm{O}
$$

and implies about $50 \mathrm{MJ} / \mathrm{kg} \mathrm{C}_{6} \mathrm{H}_{14}$ with a stoichiometric coefficient of 3.6.

We use off the shelf equipment, i.e. for turbines, the maximum temperature was set equal to $1323 \mathrm{~K}\left(1050^{\circ} \mathrm{C}\right)$. To utilize the benefits of $\mathrm{CO}_{2}$, the pressure was set at 100 bar. The results are presented in the Table 1.

Table. 1 The results of cycle calculations for a net power of $10 \mathrm{MW}$.

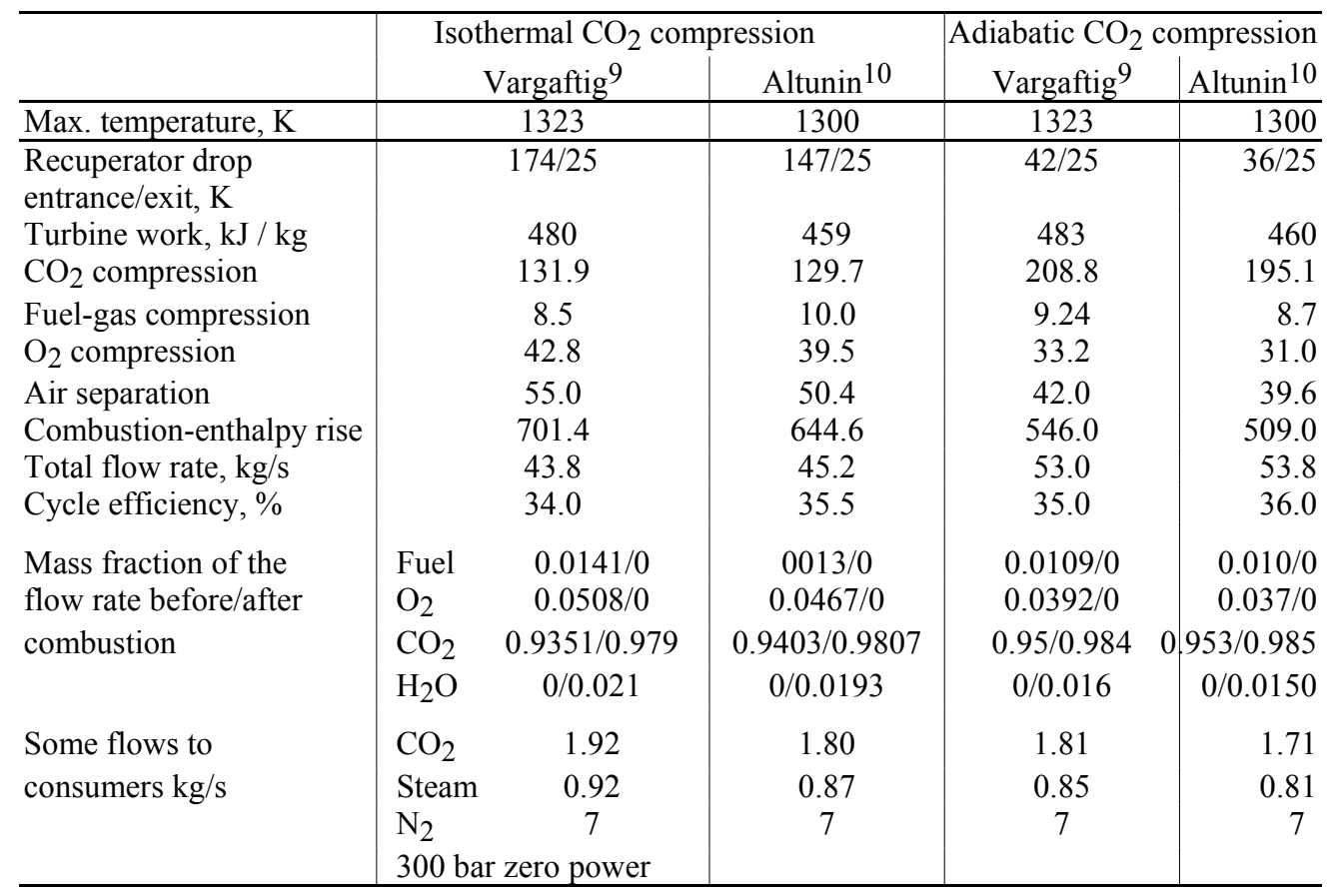

An efficiency calculation for the last column gives (460-195.1-8.7-31.0-39.6)/509 0.36 . The isentropic turbine efficiency was assumed to be 0.85 , which is realistic for a gas turbine without cooling. We have considered both isothermal and adiabatic compression of $\mathrm{CO}_{2}$ in unit 10 , with an internal efficiency of 0.85 . The isothermal, multistage, intercooled compressor consumes less power. However, according to Degtiarev, ${ }^{13}$ if we increase the $\mathrm{CO}_{2}$ temperature after removing the compression heat, the entrance temperature difference in the main recuperator will decrease. This process allows us to decrease exergy losses and the total cycle efficiency is increased in spite of greater compressor work. (see the lady-boot-like cycle in Fig. 4). 
Figure 5 shows the bottom part of the $\mathrm{CO}_{2}$ cycle in greater detail. The solid line reflects adiabatic compression. For isobaric cooling, additional recuperators are used. The isothermal case is shown by the dotted line. In effect, the horizontal line consists of many teeth describing multistage compression. The enthalpy of $\mathrm{CO}_{2}$ vapor at the end of compression is much less than at the start, which reflects non-ideal gas behavior.

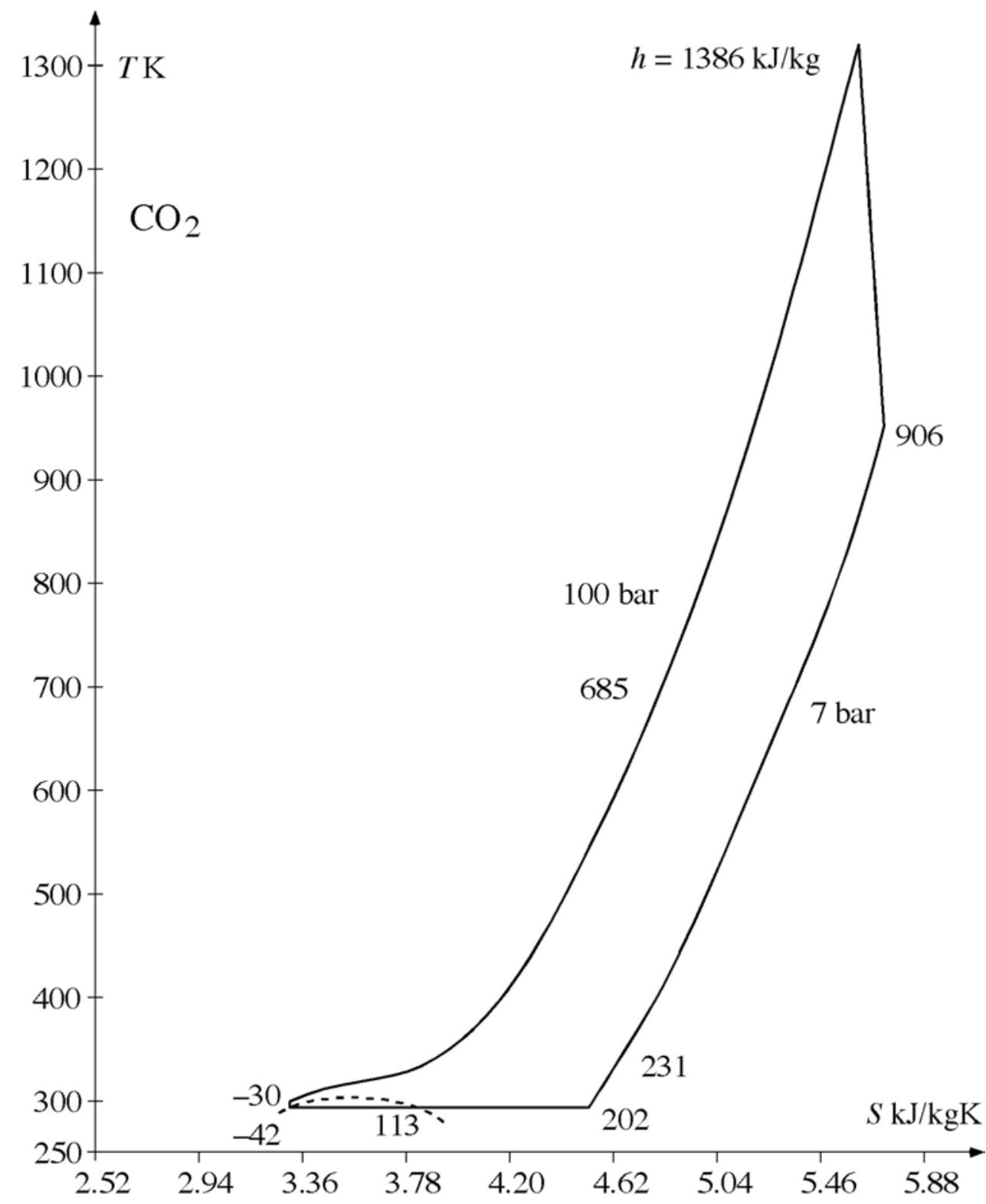

Fig. 3. T-S diagram of the cycle with isothermal compression.

In our case, the steam content is less than $2 \%$ and we therefore neglect the steam in this first study. The lack of thermodynamic tables for mixtures of $\mathrm{CO}_{2}$ and steam makes computer simulations necessary. For $\mathrm{CO}_{2}$, there exist discrepancies in different tables (see Table 1); the influence of these discrepancies on our results is illustrated in Table 1. Data are based on Vargaftig 9 and Altunin. ${ }^{10}$ The evident differences are admissible first approximations. 
In offshore use, the mass of the OCDOPUS plant, which is dominated by recuperator 3 , may be of primary importance. In our case, the recuperator weighs about 61.4 tons, the heat transfer is $29.1 \mathrm{MW}$, and the surface area is $5990 \mathrm{~m}^{2}$. The masses of the power plant and of the air-separation unit are estimated to be 100 tons each, i.e. the total mass is 200 tons or about $20 \mathrm{~kg} / \mathrm{kW}$. This is a representative figure for heavy-duty plants. More rigorous calculations should be performed in the future.

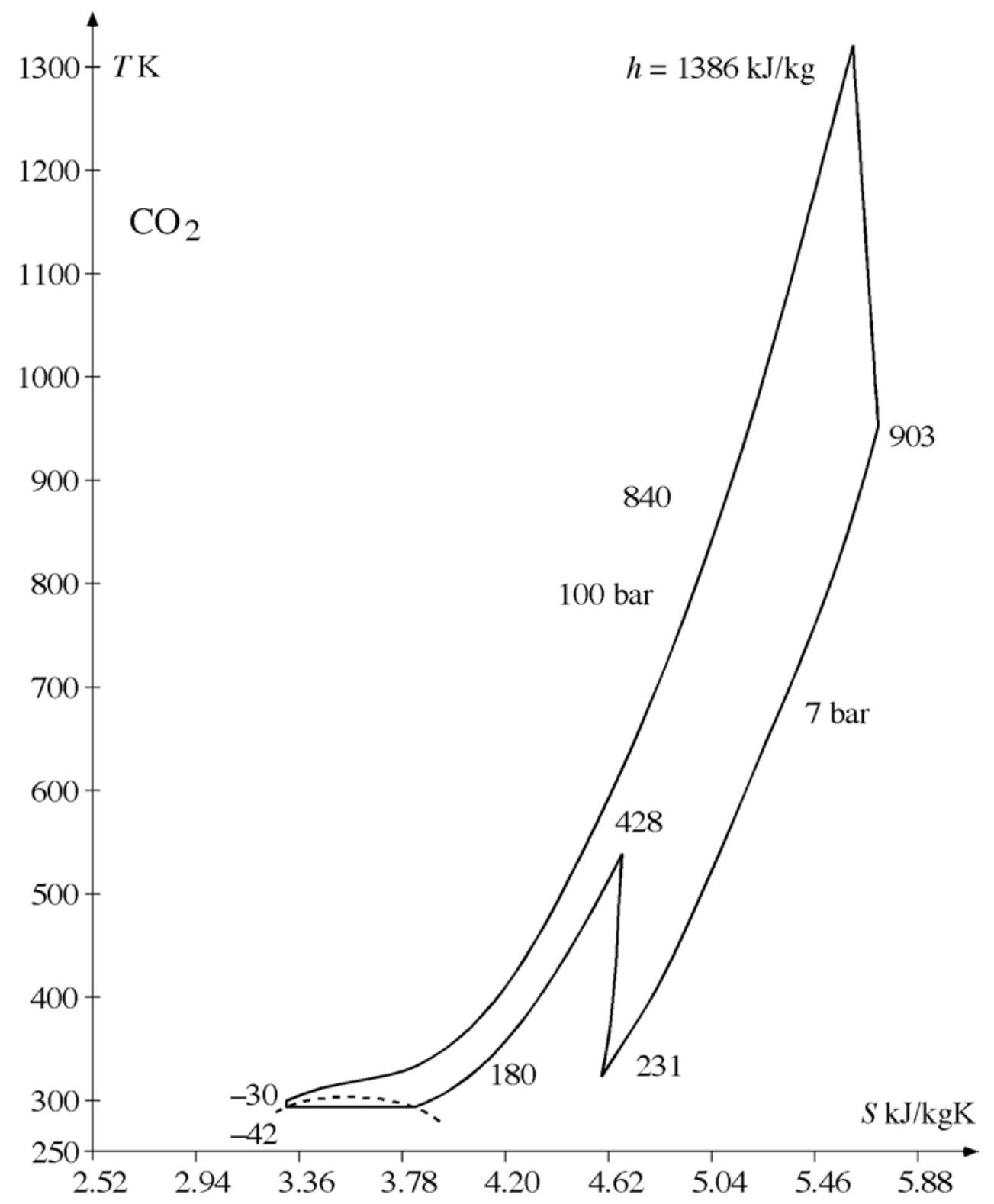

Fig. 4. T-S diagram of the cycle with adiabatic compression and additional recuperators.

\section{CONCLUSIONS}

The preliminary study of the OCDOPUS concept have shown that it is a promising concept and merits further studies. With a temperature at the turbine inlet of $1050^{\circ} \mathrm{C}$, a pressure range of 7 to 100 bars, and a turbine efficiency of $85 \%$, the efficiency becomes about $35 \%$, and no exhaust gases are released from the plant. If the prediction of 10:1 oilrecovery to $\mathrm{CO}_{2}$-injection ratio is valid, daily extraction of 1000 tons of crude oil is 
possible; if the ratio is only $0.5: 1$ extraction becomes 50 tons. The daily fuel consumption $(0.538 \mathrm{~kg} / \mathrm{s})$ of the $10 \mathrm{MW}$ plant is just 50 tons. Therefore, a ratio of $0.5: 1$ is admissible when gaseous fuel is used and prohibitively low in case of crude oil combustion.

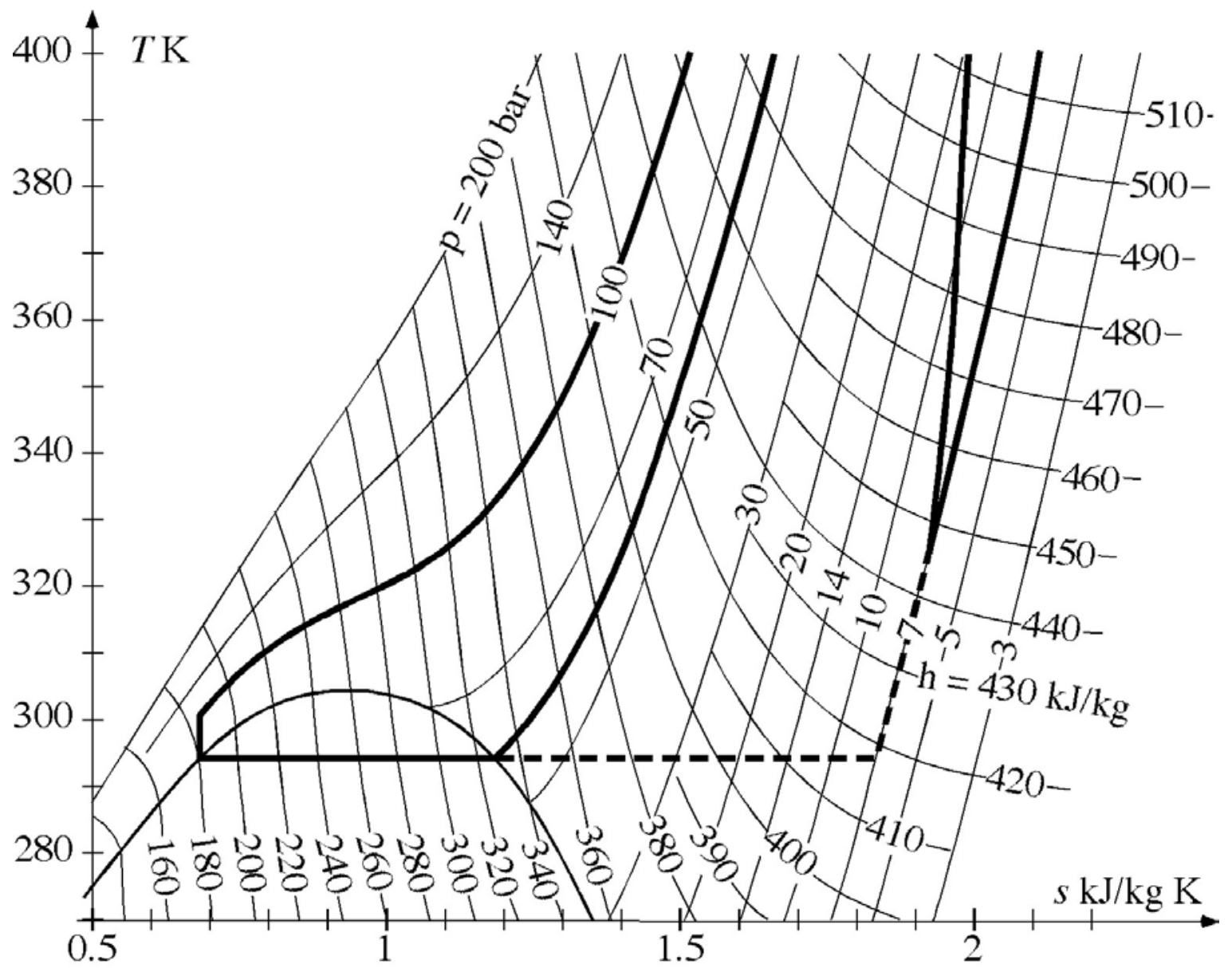

Fig. 5. T-S diagram of the cycle with adiabatic compression and additional recuperators.

\section{REFERENCES}

1. D. P. Hochstein, Soviet Boiler and Turbine Construction (in Russian), No. 10, 420 (1940).

2. V. L. Degtiarev and V. P. Gribovski, "Carbon Dioxide Semi-Closed Power Plant," Bullet. of Inventions (Nov. 12, 1971).

3. P. Pechtl, Erdöl und Kohle Petrochemie, No. 4, 159 (1991).

4. E. I. Yantovskii, "The Thermodynamics of Fuel-Fired Power Plants without Exhaust Gases," World Clean Energy Conf. CMDC, Geneva (Nov. 4-7, 1991).

5. J. De Ruyck, Energy Conversion and Mgmt. 33, 397 (1992).

6. P. van Steenderen, "Carbon Dioxide Recovery from Coal Gas and Natural Gas Fired Combined Cycle Power Plants by Combustion in Pure Oxygen and Recycled Carbon Dioxide," COMPRIMO Consulting Services BV, information for participants at the First Intern. Conf. on $\mathrm{CO}_{2}$ Removal, 4-6 March, Amsterdam (1992).

7. O. Bolland and S. Saether, Energy Conversion and Mgmt. 33, 467 (1992).

8 T. Holt and E. Lindeberg, Energy Conversion and Mgmt. 33, 595 (1992).

9. N. B. Vargaftig, Handbook on Thermophysical Properties of Gases and Liquids (in Russian), Physmathgiz, Moscow (1963).

10. V. V. Altunin, Thermophysical Properties of Carbon Dioxide (in Russian), Standard Publishers, Moscow (1975) 
11. The Economic Commission for Europe and Energy Conversion, "Recent Experience and Prospects. Improved Recovery of Liquid and Gaseous Hydrocarbons from Underground Deposits," United Nations, NY (1980).

12. V. G. Scripka and E. S. Gervits, Oil Production and Transport (in Russian), No. 10, Moscow (1984).

13. V. L. Degtiarev, Thermal Engineering, No. 12 Moscow (1967). 